EXPERIMENTAL STUDY

\title{
Forskolin and dexamethasone synergistically induce aromatase (CYP19) expression in the human osteoblastic cell line SV-HFO
}

\author{
Masatada Watanabe, Shuji Ohno and Shizuo Nakajin \\ Department of Biochemistry, Hoshi University School of Pharmacy and Pharmaceutical Sciences, 2-4-41 Ebara, Shinagawa, Tokyo 142-8501, Japan
}

(Correspondence should be addressed to M Watanabe; Email: mastada@hoshi.ac.jp)

\begin{abstract}
Objective: Recent progress supports the importance of local estrogen secretion in human bone tissues to increase and maintain bone mineral density. In a previous study, we reported that the expression of aromatase (CYP19) is dexamethasone (Dex)-dependent and oncostatin M (OSM) increases the expression synergistically with Dex. In the present study, we examined the effects of forskolin (FSK) as another potential synergistic factor.

Results: Co-administration of $100 \mathrm{nM}$ Dex and $10 \mu \mathrm{M}$ FSK increased aromatase activity 4-fold compared with Dex alone. The results of reverse transcriptase (RT)-PCR suggest that the amount of CYP19 gene transcript was also up-regulated by FSK synergistically with Dex, and that promoter I.4, which is not activated by FSK alone, is activated by FSK synergistically with Dex. The results of RT-PCR also suggest that promoter II, which responds to FSK, was not activated even in the presence of FSK in SV-HFO. The promoter I.4 sequence that was transfected into SV-HFO was activated by FSK synergistically with Dex.

Conclusions: Synergistic up-regulation of aromatase activity, CYP19 gene transcript, and promoter I.4 activity were Dex-dependent and not up-regulated by FSK alone. The results of this work may form the basis of bone-specific estrogen-replacement therapy that increases the estrogen concentration in bone tissue only.
\end{abstract}

European Journal of Endocrinology 152 619-624

\section{Introduction}

Recent progress supports the importance of local estrogen secretion in human bone tissue to increase and maintain bone mineral density $(1-4)$. Immunohistochemistry and in situ hybridization have revealed that aromatase (CYP19) is expressed in osteoblasts, osteocytes, lining cells, and chondrocytes (5). Aromatase (CYP19) is the rate-limiting enzyme of estrogen biosynthesis. Aromatase is coded by the CYP19 gene. Male patients with defects in the CYP19 gene and severe osteopenia and loss of epiphyseal closure have been reported (2). In addition, according to recent reports, there is a correlation between the polymorphism of repeat sequence in the CYP19 gene and bone density in postmenopausal women (6). These reports suggest the importance of local aromatase activity in the increase and maintenance of bone density, because the main source of estrogen in men and postmenopausal women is aromatase activity in bone tissue.

With respect to the expression of aromatase in human bone cells, there have been reports using primary human osteoblasts and cell lines that were established from human osteoblasts $(7,8)$. The aromatase activities and CYP19 gene transcripts in these cells were up-regulated in a glucocorticoid-dependent fashion. Among several tissue-specific promoters in the CYP19 gene (Fig. 1) (9-11), promoter I.4, which has a glucocorticoid-response element (GRE), is dominantly activated. In addition, oncostatin M (OSM) has been reported to up-regulate aromatase expression in synergy with synthetic glucocorticoid dexamethasone (Dex) in these cells (8).

Recently, we investigated the expression of aromatase activity and CYP19 gene transcript in the human osteoblastic cell line SV-HFO (12). The SV-HFO cell line was established from human fetal calvaria, and retains the features of human osteoblasts well (13). Aromatase activity and gene transcript were detected in SV-HFO (14). Aromatase activity and CYP19 gene transcript were up-regulated in a Dex-dependent manner. Promoter I.4 is activated in this up-regulation. Dex and OSM also synergize in SV-HFO cells. Aromatase activity in the presence of $100 \mathrm{nM}$ Dex and $5 \mathrm{ng} / \mathrm{ml}$ OSM was about 6-fold compared with the activity in the presence of Dex alone. Based upon this, we attempted to identify other synergistic up-regulators for aromatase expression in SV-HFO. 


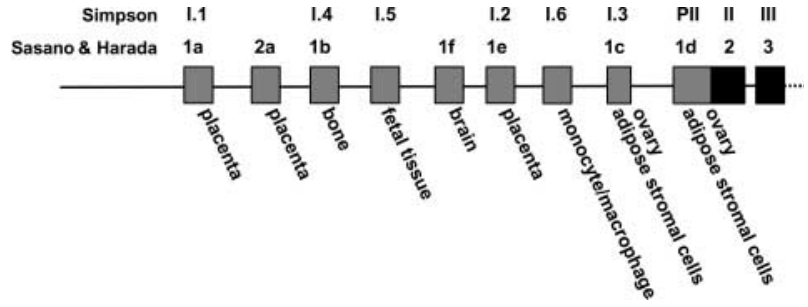

Figure 1 Partial structure of human CYP19 gene. Gray boxes represent multiple tissue-specific exon I. Black boxes represent exon II and exon III. Nomenclature for exons is according to Simpson et al. (11) and Sasano \& Harada (9). Well-known tissues in which each exon I is selected are indicated. Positions of each exon I are based upon Sebastian \& Bulun (10).

In the present study, we examined if forskolin (FSK) could up-regulate aromatase expression in synergy with Dex in SV-HFO cells. FSK is a well-known up-regulator of the genes of enzymes that are involved in steroid metabolism. FSK alone could not up-regulate aromatase expression in SV-HFO cells (12). Therefore, in the present study, we examined the effects of Dex and FSK administered in combination.

\section{Materials and methods}

\section{Materials}

Dex and FSK were obtained from Wako Pure Chemical Industries (Osaka, Japan), RPMI 1640 medium from Sigma (St Louis, MO, USA), RPMI 1640 medium without Phenol Red and penicillin/streptomycin from Invitrogen (Carlsbad, CA, USA), fetal bovine serum from Sanko Junyaku (Tokyo, Japan), and $\left[1 \beta-{ }^{3} \mathrm{H}\right]$ androstenedione from Perkin-Elmer Corp. (Boston, MA, USA).

\section{Cells}

SV-HFO, a human fetal osteoblastic cell line, was generous gift from Dr Hideki Chiba (Sapporo Medical University, Hokkaido, Japan). The cells were cultured in RPMI 1640 medium supplemented with 10\% fetal bovine serum, penicillin, and streptomycin at $37^{\circ} \mathrm{C}$ and $5 \% \mathrm{CO}_{2}$.

\section{Aromatase assay}

Cells were seeded into 24-well plates at a density of $2.0 \times 10^{5} \mathrm{cells} / \mathrm{ml}$ and $500 \mu \mathrm{l} /$ well. After 2 days of culturing, cells were treated with the RPMI 1640 medium without Phenol Red for $24 \mathrm{~h}$ (serum starvation). Then the medium was changed to RPMI 1640 medium containing Dex and FSK and incubated for $24 \mathrm{~h}$. Dex and FSK were dissolved in ethanol and a $0.1 \%$ volume of solution was added to the medium. Aromatase activity in the cells was measured according to the methods used in a previous study (15).

\section{Reverse transcriptase (RT)-PCR}

Total RNA of the cells was extracted using ISOGEN (Nippongene, Toyama, Japan). First-strand cDNA was prepared using avian myeloblastosis virus RT (Promega, Madison, WI, USA). The amplification of human CYP19 gene transcript using the primers derived from exon II, exon III, exon I.4, exon PII, and glyceraldehyde-3-phosphate dehydrogenase (GAPDH) was performed as described previously (15). Amplification of the gene transcripts of human glucocorticoid receptor (hGR) $\alpha$ was performed using hGR forward primer (5'-ACACAGGCTTCAGGTATCTT-3') and hGR $\alpha$ reverse primer $\left(5^{\prime}\right.$-ACTGCTTCTGTTGCCAAG-3') with the following program: $94^{\circ} \mathrm{C}$ for $5 \mathrm{~min}$; 30 cycles of $94{ }^{\circ} \mathrm{C}$ for $40 \mathrm{~s}, 54^{\circ} \mathrm{C}$ for $40 \mathrm{~s}$, and $72{ }^{\circ} \mathrm{C}$ for $40 \mathrm{~s} ; 72^{\circ} \mathrm{C}$ for $5 \mathrm{~min}$. PCR products were visualized by the luminescence of ethidium bromide by ultraviolet rays after electrophoresis in 1.5\% agarose gel. The expression levels of the aromatase coding region (primers derived from exons II and III were used) and GR $\alpha$ were calculated by dividing the optical density of the bands for the aromatase coding region or GR $\alpha$ by the optical density of the band for GAPDH.

\section{Promoter I.4 firefly luciferase reporter construct}

Promoter I.4 sequences were amplified using Pfu turbo DNA polymerase (Stratagene, La Jolla, CA, USA) and PI.4-S1 (5'-CGGGGTACCCTCTGGTCAGATATTTTGATCATGC-3'), PI.4-S2 (5'-CGGGGTACCTAGGGGTGAGACACTTAGGC-3'), PI.4-S3 (5'-CGGGGTACCGCTGTATGGTCAGCTTGGGG-3'), PI.4-S4 (5'-CGGGGTACCCCTGAAAGAATGTCAGCTCG-3'), and PI.4-AS1 (5'-TCCCCCGGGCCAGTTGGTCACGTTCTACTTGG-3'). Human genome DNA (Promega) was used as the template. After the treatment with KpnI and SmaI, the PCR products were subcloned into pGL3-Basic (Promega).

\section{Transfection and luciferase assay}

Cells were seeded at a density of $2.0 \times 10^{5}$ cells $/ \mathrm{ml}$ and $500 \mu \mathrm{l} /$ well. After $24 \mathrm{~h}$ culturing, firefly luciferase reporter vector and sea-pansy luciferase internal control vector phRL-TK (Promega) were transiently transfected using Fugene6 transfection reagent (Roche, Mannheim, Germany). After $16 \mathrm{~h}$ transfection, the cells were serum starved for $4 \mathrm{~h}$ and treated with various agents for $4 \mathrm{~h}$. After treatment, the firefly luciferase and sea-pansy luciferase activities were measured using a Dual luciferase reporter assay kit (Promega) and a Sirius luminometer (Berthord, Pforzheim, Germany). Promoter activity was calculated by dividing firefly luciferase reporter activity by sea-pansy luciferase internal control activity. 


\section{Statistical analysis}

Statistically significant differences between the experimental groups were determined by one-way ANOVA followed by Fisher's protected least-significant difference multiple comparison (Fisher's PLSD multiple comparison) or Dunett's multiple comparison. Statistical analysis was performed using the software program StatView 5.0 (SAS Institute, Cary, NC, USA) or Prism 4 for Windows (GraphPad Software, San Diego, CA, USA). The point of minimal statistically significant difference was set at $P \leq 0.05$.

\section{Results}

\section{FSK and Dex synergistically up-regulate aromatase activity in SV-HFO cells}

We examined the effects of FSK on aromatase activity in SV-HFO cells. As shown in Fig. 2, aromatase activity in the presence of $100 \mathrm{nM}$ Dex was $3.75 \mathrm{pmol} / \mathrm{mg}$ protein per $6 \mathrm{~h}$, and the addition of FSK increased aromatase activity in a dose-dependent manner. When $10 \mu \mathrm{M}$ FSK was added, aromatase activity increased about 4fold $(15.2 \mathrm{pmol} / \mathrm{mg}$ protein per $6 \mathrm{~h})$ compared with Dex alone. Aromatase activity was not up-regulated in the presence of $10 \mu \mathrm{M}$ FSK alone. These results suggest that the up-regulation of aromatase activity by FSK depends upon Dex.

\section{Expression of CYP19 gene transcript}

In a previous study, we showed that the up-regulation of aromatase activity in SV-HFO cells in the presence of Dex and OSM was the result of up-regulation of CYP19 gene transcript (12). Based upon this observation, we attempted to determine if the amount of CYP19 gene transcript changed in the presence of FSK. As shown in Fig. 3, the amount of CYP19 gene transcript increased in the presence of $100 \mathrm{nM}$ Dex.

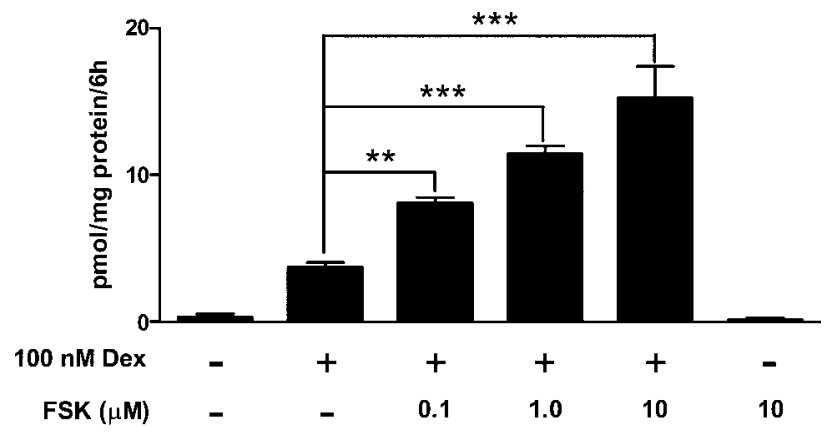

Figure 2 Aromatase activity in SV-HFO cells was increased by FSK in the presence of Dex. After $24 \mathrm{~h}$ serum starvation, SV-HFO cells were treated with media that included Dex and FSK, as indicated, for $24 \mathrm{~h}$. Experiments were performed in triplicate. Statistical significance was analyzed by one-way ANOVA followed by Fisher's PLSD multiple comparison. Error bars represent the S.E.M.; ${ }^{\star *} P<0.01,{ }^{* * *} P<0.001$
(A)

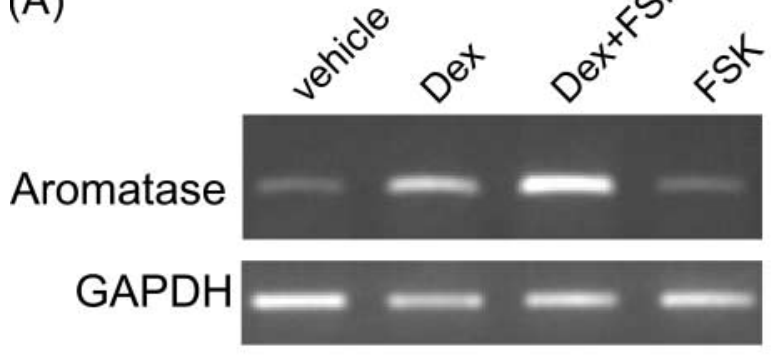

(B)

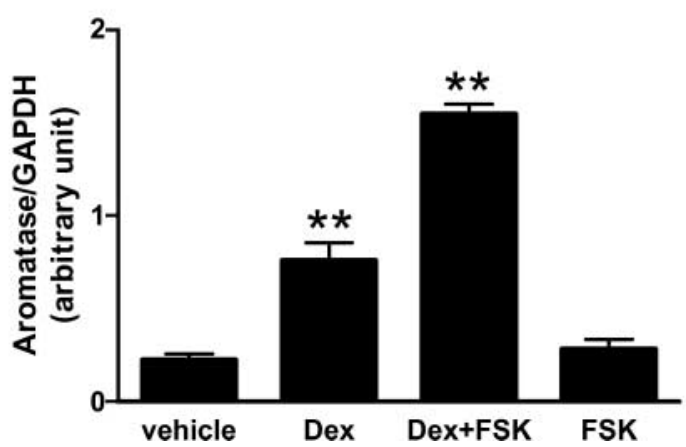

Figure 3 Synergistic effects of Dex and FSK upon the expression of CYP19 gene transcript. (A) After $24 \mathrm{~h}$ serum starvation, SVHFO cells were treated with media that included ethanol (vehicle), $100 \mathrm{nM}$ Dex, and $10 \mu \mathrm{M}$ FSK, as indicated, for $24 \mathrm{~h}$. After the extraction of total RNA, RT-PCR of CYP19 coding region and GAPDH gene were performed. (B) Expression of CYP19 coding region was quantified as described in the Materials and methods section. Experiments were performed in triplicate. Statistical significance was analyzed by one-way ANOVA followed by Dunett's multiple comparison. Error bars represent the S.E.M.; ${ }^{* \star} P<0.01$.

The addition of $10 \mu \mathrm{M}$ FSK further increased the amount of CYP19 gene transcript. The amount of CYP19 gene transcript did not change in the presence of FSK alone. Then we examined which form of exon I is selected in the presence of Dex and FSK. Previously, we showed that exon I.4, not exon PII, is selected in SVHFO cells (12). However, promoter II, which can be activated by FSK, may be activated and a gene transcript containing exon PII could therefore be produced. In Fig. 4, it seems that only exon I.4-containing gene transcript appears, even in the presence of FSK. This result suggests that the exon I selected in the presence of Dex and FSK is exon I.4. These results also suggest that promoter I.4, which abuts the $5^{\prime}$ end of exon I.4, is activated. FSK alone did not induce CYP19 gene expression (Figs. 3 and 4). Therefore, the response to FSK at the stage of gene expression also depends upon Dex.

\section{Synergism of Dex and FSK upon promoter I.4}

Based upon the RT-PCR data, we determined if promoter $\mathrm{I} .4$ could be up-regulated by the combination of Dex and FSK in SV-HFO cells by the tranfection of firefly 


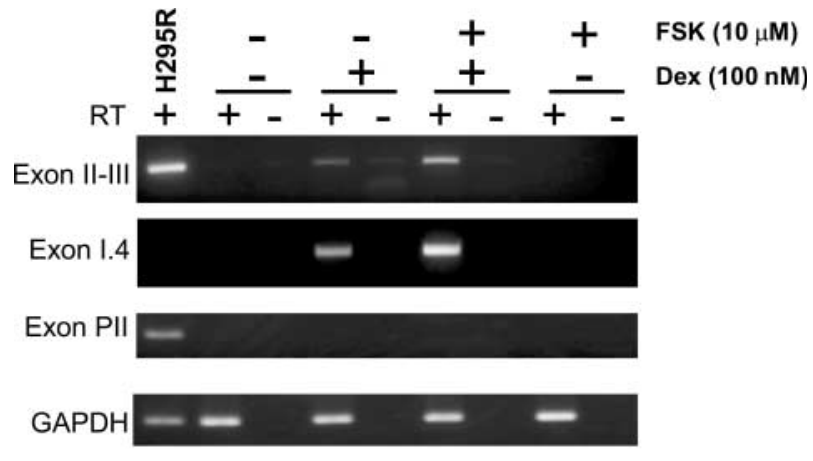

Figure 4 Expression of CYP19 gene transcripts in SV-HFO cells. After $24 \mathrm{~h}$ serum starvation, SV-HFO cells were treated with media that included Dex and FSK, as indicated, for $24 \mathrm{~h}$. After the extraction of total RNA, RT-PCR was performed. RT + and RT - indicate cDNA preparation with or without RT, respectively. GAPDH gene transcript was used as an internal control. Total RNA from the human adrenocortical carcinoma cell line H295R treated with FSK was used as a positive control for exon II-III (CYP19 gene coding region) and exon PII-containing gene transcripts.

reporter vector, which harbors the sequence of promoter I.4 in SV-HFO cells. As shown in Fig. 5, we prepared four reporter vectors harboring various $5^{\prime}$-deleted sequences of promoter I.4. First, we transfected the sequence $-1004 /+14$ into SV-HFO cells and treated the cells with $100 \mathrm{nM}$ Dex and various concentrations of FSK. As shown in Fig. 6, the activity of promoter I.4 was up-regulated by Dex and the addition of FSK increased promoter activity in a dose-dependent fashion. However, $10 \mu \mathrm{M}$ FSK alone could not up-regulate the promoter activity. Therefore, the effects of FSK depend upon the presence of Dex at the stage of promoter I.4 up-regulation as well. An empty vector with no promoter sequence (Basic) did not respond to Dex or FSK.

\section{Synergistic effect of Dex and FSK on various lengths of promoter $\mathrm{I.4}$}

To estimate the important sequence for the synergism of Dex and FSK upon promoter I.4, we transfected reporter vectors that harbor various $5^{\prime}$-deleted promoter I.4 sequences and determined the promoter activities in the presence of Dex alone or Dex + FSK. As shown in Fig. 7, promoter activity declined as the $5^{\prime}$ sequence was deleted. This decline of promoter activity would be caused by the deletion of the sequences that are not critical but important for the activity of promoter I.4 (for example, activator protein-1 (AP1) and interferon- $\gamma$-activated site (GAS)). The sequences $-683 /+14$ and $-458 /+14$, which contain a GRE, responded to Dex, and the addition of FSK further increased the promoter activity. Sequence $-304 /+14$, which has no GRE, was not significantly activated by Dex or Dex + FSK. These results suggest that GRE is important for the synergism of FSK with Dex. FSK alone could not activate any length of promoter I.4.

\section{Expression of GRs is not affected by FSK}

One possible mechanism for the increase in aromatase expression in the presence of Dex and FSK is an increase in GR expression in response to FSK. We examined the amount of GR gene transcript in the presence and absence of FSK using RT-PCR. As shown in

\section{Promoter I.4 sequence}

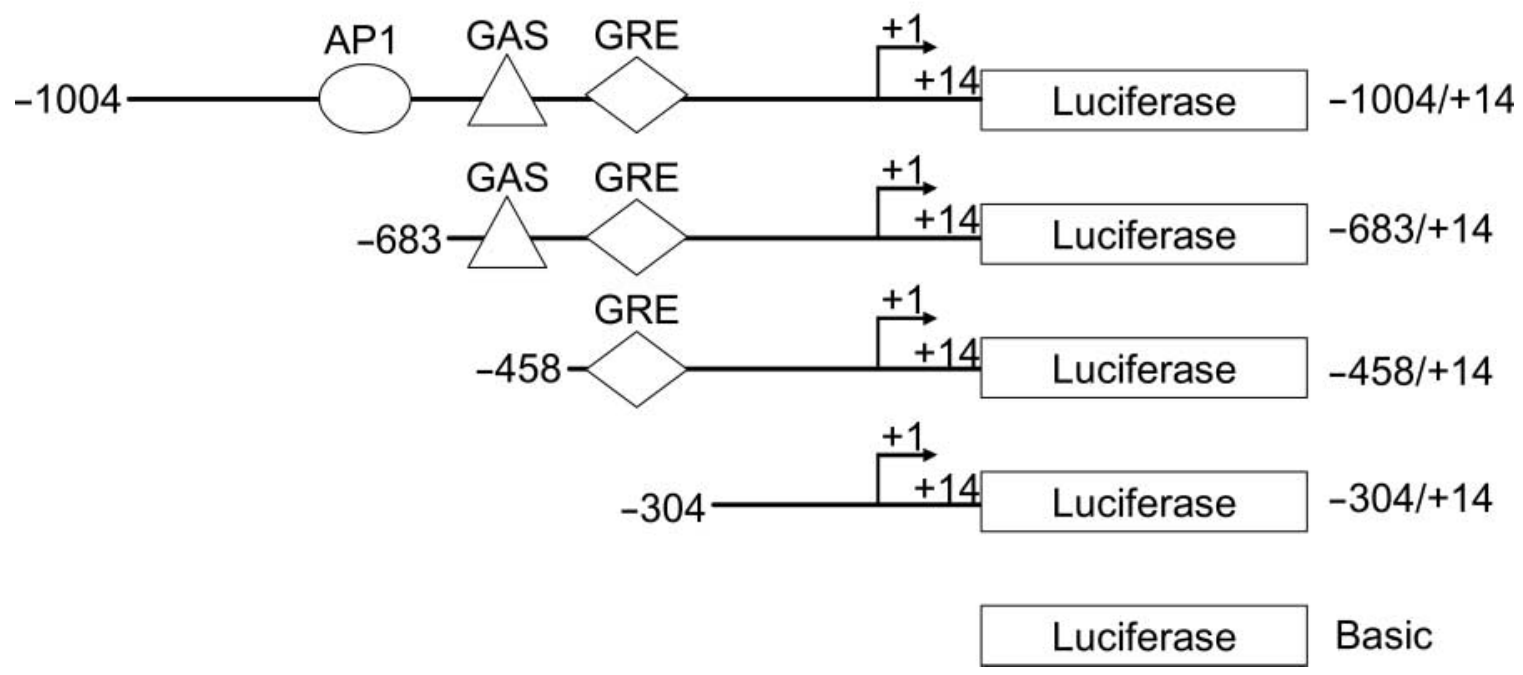

Figure 5 Firefly luciferase reporter vectors harboring promoter I.4 sequences. Several lengths of promoter I.4 sequence were placed upstream of firefly luciferase gene of pGL3-Basic (Basic). Positions of well-known transcription factor-binding sites, activator protein-1 (AP1), interferon- $\gamma$-activated site (GAS), and GRE, are indicated. +1 denotes the transcription start site. Numbers indicate positions (in bp) relative to the transcription start site. 


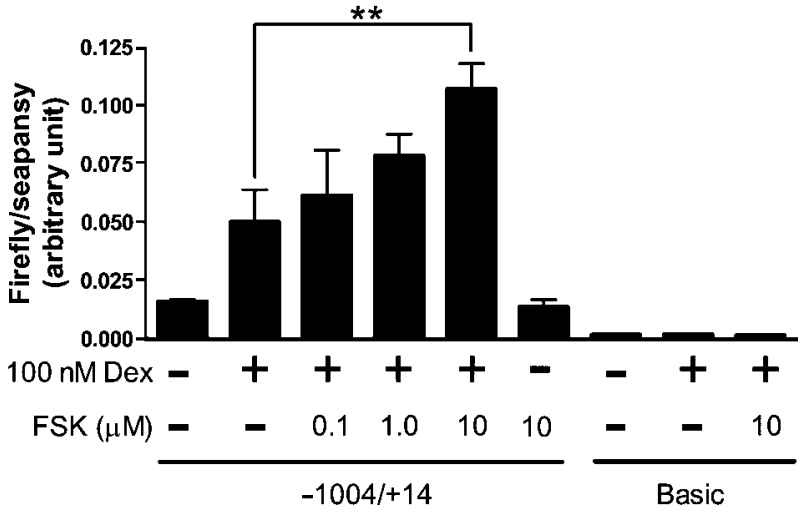

Figure 6 Promoter I.4 responds to FSK in the presence of Dex. SV-HFO cells were transfected with sequence $-1004 /+14$ or pGL3-Basic (Basic) and phRL-TK for $16 \mathrm{~h}$. After $4 \mathrm{~h}$ serum starvation, the cells were treated with media containing Dex and FSK, as indicated, for $4 \mathrm{~h}$. Firefly luciferase activity and sea-pansy luciferase activities in the cell lysates were measured. Experiments were performed in triplicate. Statistical significance was analyzed by one-way ANOVA followed by Fisher's PLSD multiple comparison. Error bars represent the S.E.M.; ${ }^{* \star} P<0.01$.

Fig. 8, the expression level of GR did not increase significantly in the presence of Dex and FSK. This result would suggest that the increase of GR expression is not the mechanism of synergism of Dex and FSK.

\section{Discussion}

Recent progress suggests the importance of local estrogen secretion in human bone tissue to increase and maintain bone mineral density. The amount of estrogen secreted in human bone tissue would not always be constant. For example, the amount of estrogen secreted in bone tissue could increase during periods in which a

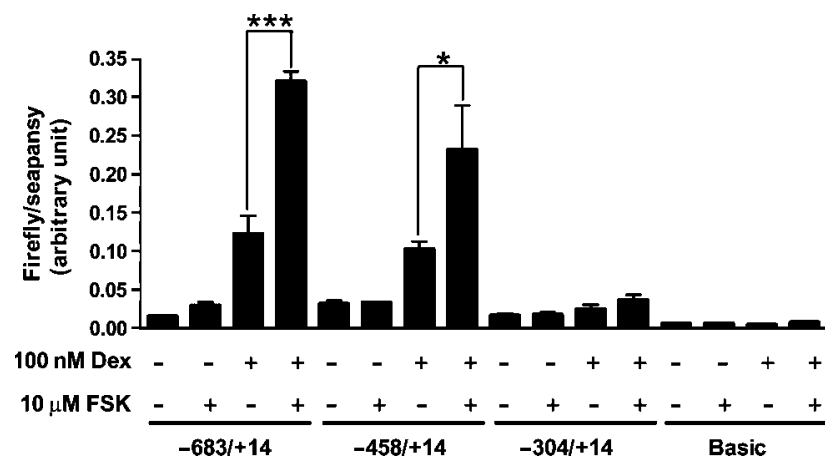

Figure 7 Activities of $5^{\prime}$-deleted series of promoter I.4. Firefly luciferase reporter vectors harboring various $5^{\prime}$-deleted series of the promoter I.4 sequence or pGL3-Basic (Basic), as indicated in Fig. 5, and phRL-TK were transfected into SV-HFO cells for $16 \mathrm{~h}$. After $4 \mathrm{~h}$ serum starvation, the cells were treated with media containing Dex and FSK, as indicated, for $4 \mathrm{~h}$. Firefly lucifarase activity and sea-pansy luciferase activities in the cell lysates were measured. Experiments were performed in triplicate. Statistical significance was analyzed by one-way ANOVA followed by Fisher's PLSD multiple comparison. Error bars represent the S.E.M.; ${ }^{\star} P<0.05,{ }^{* \star \star} P<0.001$
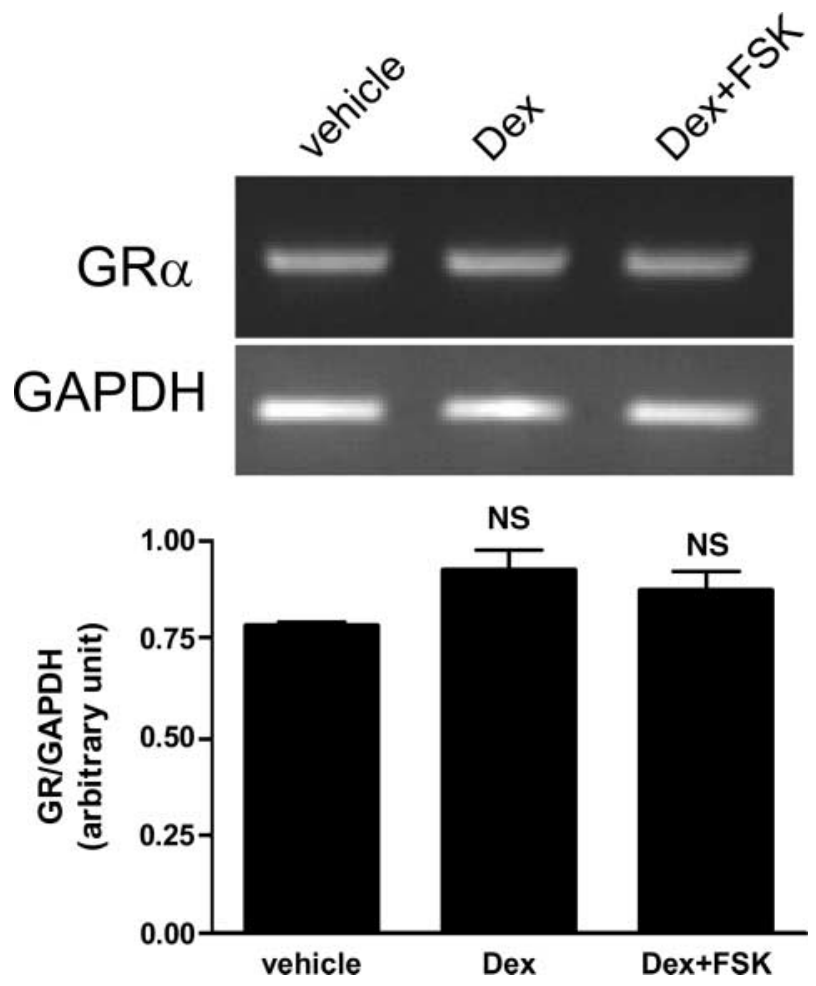

Figure 8 Expression of GR $\alpha$ in SV-HFO cells. (A) After $24 \mathrm{~h}$ serum starvation, cells were treated with ethanol (vehicle), $100 \mathrm{nM}$ Dex, and $10 \mu \mathrm{M}$ FSK for $24 \mathrm{~h}$. RT-PCR was performed as described in the Materials and methods section. (B) Expression of $\mathrm{GR} \alpha$ was quantified as described in the Materials and methods section. Experiments were performed in triplicate. Statistical significance was analyzed by one-way ANOVA followed by Dunett's multiple comparison. Error bars represent the S.E.M. NS, not significant in comparison with vehicle.

rapid increase in bone mineral density is required, such as new bone formation or fracture healing. Cytokines or low-molecular-mass factors would control the amount of estrogen secreted by controlling the expression level of aromatase in bone tissue.

In the present study, we found that FSK increases aromatase activity in SV-HFO cells in synergy with Dex. The results of RT-PCR suggest that this increase in aromatase activity is caused by an increase in CYP19 gene transcript (Fig. 3). The RT-PCR results also suggest that promoter I.4, which has been thought until now not to be activated by FSK, is activated by FSK in the presence of Dex, whereas promoter II, which is activated by the signaling pathway that involves cAMP, is not activated even in the presence of FSK in SV-HFO cells. In agreement with the RTPCR results, promoter I.4 that was transfected into SV-HFO cells was synergistically activated by Dex and FSK (Fig. 6).

One of the possible mechanisms of the synergism of Dex and FSK is the up-regulation of GR expression in response to FSK. An increased amount of GR may increase the activity of promoter I.4. Because the pro- 
moter of human GR gene has a cAMP-response element (CRE) (16), CRE-binding protein (CREB), which can be activated by FSK via an increase in intracellular cAMP level and activation of protein kinase A, may up-regulate GR gene expression. Based on the results of RT-PCR (Fig. 8), we concluded that the GR gene expression level does not change in the presence of Dex and FSK in SV-HFO cells. Therefore, an interaction between GR and another transcription factor that responds to cAMP is the most likely mechanism of this synergism. Among the cAMP-responsive transcription factors, it was found that at least CREB is expressed in SV-HFO cells (results not shown).

Aromatase activity, the amount of CYP19 gene transcript, and the activity of promoter I.4 respond to FSK (increase the intracellular cAMP level) in the presence of Dex. There have been reports about the synergism of glucocorticoids and the CAMP signal pathway (17, 18); however, to the best of our knowledge the present study is the first to observe a glucocorticoid-dependent synergism of these signal pathways because FSK alone has no effect upon aromatase expression. Furthermore, this study is the first to describe the activation of promoter I. 4 by FSK. In the future we intend to investigate the mechanism of this synergism further.

A factor that significantly increases aromatase activity in osteoblasts, as did the combination of Dex and FSK in this study, would be beneficial, especially for the treatment of osteopenia and osteoporosis. Estrogen-replacement therapy (ERT) has been used to treat osteopenia and osteoporosis in postmenopausal women. However, ERT has various risks - for example uterine body cancer, thrombosis, and breast cancer because ERT increases estrogen levels throughout the entire body. On the other hand, a drug that increases the expression of aromatase only in osteoblasts would increase the estrogen concentration only in bone tissue and would thus most likely not affect other tissues. The present study should form the basis for the development of such a tissue-specific ERT.

\section{Acknowledgements}

We thank Dr Hideki Chiba for kindly providing the SV-HFO cell line. We thank Ms Mariko Noda for her technical assistance. This work was supported by the Ministry of Education, Culture, Sports, Sciences and Technology of Japan.

\section{References}

1 Bilezikian JP, Morishima A, Bell J \& Grumbach MM. Increased bone mass as a result of estrogen therapy in a man with aromatase deficiency. New England Journal of Medicine 1998339 599-603.

2 Carani C, Qin K, Simoni M, Faustini-Fustini M, Serpente S, Boyd J, Korach KS \& Simpson ER. Effect of testosterone and estradiol in a man with aromatase deficiency. New England Journal of Medicine $199733791-95$.

3 Maffei L, Murata Y, Rochira V, Tubert G, Aranda C, Vazquez M, Clyne CD, Davis S, Simpson ER \& Carani C. Dysmetabolic syndrome in a man with a novel mutation of the aromatase gene: effects of testosterone, alendronate, and estradiol treatment. Journal of Clinical Endocrinology and Metabolism 200489 61-70.

4 Morishima A, Grumbach MM, Simpson ER, Fisher C \& Qin K. Aromatase deficiency in male and female siblings caused by a novel mutation and the physiological role of estrogens. Journal of Clinical Endocrinology and Metabolism 199580 3689-3698.

5 Sasano H, Uzuki M, Sawai T, Nagura H, Matsunaga G, Kashimoto O \& Harada N. Aromatase in human bone tissue. J Bone Mineral Research 199712 1416-1423.

6 Masi L, Becherini L, Gennari L, Amedei A, Colli E, Falchetti A, Farci M, Silvestri S, Gonnelli S \& Brandi ML. Polymorphism of the aromatase gene in postmenopausal Italian women: distribution and correlation with bone mass and fracture risk. Journal of Clinical Endocrinology and Metabolism 200186 2263-2269.

7 Nawata H, Tanaka S, Takayanagi R, Sakai Y, Yanase T, Ikuyama S $\&$ Haji M. Aromatase in bone cell: association with osteoporosis in postmenopausal women. Journal of Steroid Biochemistry and Molecular Biology 199553 165-174.

8 Shozu M \& Simpson ER. Aromatase expression of human osteoblast-like cells. Molecular and Cellular Endocrinology 1998139 117-129.

9 Sasano H \& Harada N. Intratumoral aromatase in human breast, endometrial, and ovarian malignancies. Endocrine Reviews 1998 $19593-607$.

10 Sebastian S \& Bulun SE. A highly complex organization of the regulatory region of the human CYP19 (aromatase) gene revealed by the Human Genome Project. Journal of Clinical Endocrinology and Metabolism 200186 4600-4602.

11 Simpson ER, Zhao Y, Agarwal VR, Michael MD, Bulun SE, Hinshelwood MM, Graham-Lorence S, Sun T, Fisher CR, Qin K \& Mendelson CR. Aromatase expression in health and disease. Recent Progress in Hormone Research 199752 185-213 discussion 213-214.

12 Watanabe M, Simpson ER, Pathirage N, Nakajin S \& Clyne CD. Aromatase expression in the human fetal osteoblastic cell line SV-HFO. Journal of Molecular Endocrinology 200432 533-545.

13 Chiba H, Sawada N, Ono T, Ishii S \& Mori M. Establishment and characterization of a simian virus 40-immortalized osteoblastic cell line from normal human bone. Japanese Journal of Cancer Research 199384 290-297.

14 Janssen JM, Bland R, Hewison M, Coughtrie MW, Sharp S, Arts J, Pols HA \& van Leeuwen JP. Estradiol formation by human osteoblasts via multiple pathways: relation with osteoblast function. Journal of Cell Biochemistry 199975 528-537.

15 Watanabe M \& Nakajin S. Forskolin up-regulates aromatase (CYP19) activity and gene transcripts in the human adrenocortical carcinoma cell line H295R. Journal of Endocrinology 2004180 $125-133$.

16 Penuelas I, Encio IJ, Lopez-Moratalla N \& Santiago E. cAMP activates transcription of the human glucocorticoid receptor gene promoter. Journal of Steroid Biochemistry and Molecular Biology $19986789-94$.

17 Christoffels VM, Grange T, Kaestner KH, Cole TJ, Darlington GJ, Croniger CM \& Lamers WH. Glucocorticoid receptor, C/EBP, HNF3, and protein kinase A coordinately activate the glucocorticoid response unit of the carbamoylphosphate synthetase I gene. Molecular and Cellular Biology 199818 6305-6315.

18 Sato A, Sheppard KE, Fullerton MJ \& Funder JW. cAMP modulates glucocorticoid-induced protein accumulation and glucocorticoid receptor in cardiomyocytes. American Journal of Physiology Endocrinology and Metabolism 1996271 E827-E833.

Received 17 August 2004

Accepted 28 December 2004 